\title{
OPPORTUNITIES FOR DISTRIBUTION OF AGRICULTURAL PRODUCTS THROUGH SHORT SUPPLY CHAINS
}

\author{
M. Stanimirova*, Y. Zarev \\ University of Economics, Varna, Bulgaria
}

\begin{abstract}
The report reveals peculiarities of short supply chains of agricultural products in Bulgaria, the process of their development as well as the possibilities for support of small farms under the European Agricultural Fund for Rural Development (EAFRD) for 2014-2020. Specific data on the dynamics of implemented projects under EAFRD 2014-2020 are discussed as well as the risks and possible solutions in direct sales.
\end{abstract}

Key words: Short distribution chain; agricultural products; small agricultural enterprises

The contemporary market conditions of intense competition, accompanied by rapid technological development, place ever higher requirements on producers and traders in the agricultural branch. The evolution of food markets is a factor that encourages vendors to transform their market behavior from application of mass marketing principles to taking into accounts the individual needs, preferences and tastes of individual customers. The development of alternative food chains or networks is the focus of recent models of rural development. The increase of competitive pressure causes a review and modification of the offers and as a final result it increases the choice of the consumer.

The main objective of this report is to reveal peculiarities of short supply chains of agricultural products in Bulgaria, the process of their development as well as the possibilities for support of small farms under the European Agricultural Fund for Rural Development (EAFRD) for 2014-2020. Specific data on the dynamics of implemented projects under EAFRD 2014-2020 are discussed as well as the risks and possible solutions in direct sales.

There is no clear definition of the construction "short chains" within the realization of agricultural products in the specialized literature. Most authors (Kneafsey et al, 2013; B roderick et al., 2011; Aubert and Enjolras,

\footnotetext{
*Correspondence to: Maria Stanimirova, PhD, University of Economics - Varna, Telephone number: +359882164690, E-mail: maria_stanimirova@ue-varna.bg
}

2013) emphasize the role of farmers in identifying the characteristics of foods, realized by short chains, and the number of intermediaries in the disposal of production who are of minimal number or totally absent in this distribution channel. In addition (François M. et al., 2000), among the benefits of short chains is the fact that there are more opportunities for farmers to create additional advantages for the product (authenticity of the product, the farm it was produced and its adjacent territory) by having direct contact with consumers and increasing social contacts. The short supply chains are differentiated in the specialized literature according to different criteria. According to François M. et al. (2000) the main types of short chains are: selling directly from the farm or the place of production, including selling to tourists; mailorder selling; selling over the Internet; producers' shop; home deliveries; selling to local restaurateurs; selling to businesses; selling at fairs, local markets, shows; selling by the producer, on a separate stand, in local hypermarkets. Marsden et al. (2000) and Renting et al. (2003), identify three main types of short chain food distribution, all of which create some form of 'connection' between food consumer and producer. These are: face-toface (consumer purchases and product direct from the producer); spatial proximity (products are produced and retailed in the specific region of production) and consumers are made aware of the 'local' nature of the product at the point of sale basis; spatially extended (information about the place and processes of production is 
communicated to consumers who are outside of the region of production itself, and who may have no personal experience of that region). According to a report of the National Rural Network (NRN, 2013), collective direct sales and partnerships between producers and consumers are a form of short chains. The functioning mechanism of this type of sales focuses on joint efforts of organizations of producers and consumers and efforts by the governments of the respective countries. The cooperation in the field of organizing and participating in the so-called "Farmer markets" in large settlements and local festivals, where a larger group of consumers is reached and conditions for the realization of a larger volume of production are created, are widespread in the USA and Europe.

Short supply chains are characterized by the active involvement of farmers in the food market beyond production and such distribution channels go hand in hand with rural development (Kneafsey et al., 2013). In the context of the rural development policy, short supply chains are analyzed from the point of view of their use in the development of strategies for the sustainability of small and family farms and the local economy. The short supply chains and the development of small farms are supported by the European Agricultural Fund for Rural Development during the current 2014-2020 programming period. The development of the short chains is directly influenced by Measure 16 Cooperation, sub-measure 16.4 "Horizontal and vertical cooperation among supply chain actors for the establishment and development of short supply chains and local markets" which supports the direct supply of small quantities of raw materials and foods of plant origin and organizations that carry out collective projects, related to the development of short supply chains or a local market association. Attention is drawn to the fact that at present farmers in Bulgaria are not sufficiently aware of the funding opportunities under schemes and measures, directly related to the agricultural activities carried out, and in particular with the sub-measure 16.4 of the RDP 2014-2020. The district of Varna can be used as an example, as for the period from 01 January 2014 to 30 June 2017 there was not one consultation to farmers regarding the indicated sub-measure, carried out by the Territorial District Office (TDO) of the National Agricultural Advisory Service (NAAS). The lack of interest in the submeasure 16.4 is also caused by its absence from the indicative reception schedule until 01 January 2017.

Surveys conducted among farmers show (Stanimirov, E. and M. Stanimirova, 2014) that they need foremost to improve their position in negotiating with traders, retailers, suppliers and other businesses with a greater market power than theirs; to control and reduce their expenditures; to expand the access to information on new products and markets; to achieve higher quality of manufactured products (including services).

Sub-measure 4.2 "Investments in processing / marketing of agricultural products" of the Rural development program 2014-2020 directs the support to the modernization of the physical assets of enterprises processing agricultural products in order to produce new and quality products, including those related to short supply chains. This also applies to submeasures 6.1 "Business start-up aid for young farmers" and 6.3 "Start-up aid for the development of small farms". These submeasures support investments related to the development and modernization of the farm as well as running costs necessary for the implementation of the business plan. The implementation of the sub-measures aims at economic development and the strengthening of small farms into sustainable and viable units, including the involvement of young people in agriculture (sub-measure 6.1).

For the purposes of this publication, secondary data are collected about the consultations carried out by a certain TDO of the NAAS (district of Varna), on the basis of which conclusions can be drawn for the interest of the producers towards the development of short supply chains. The data in Table $\mathbf{1}$ show that a total of 1480 consultations were carried out within the period 2014-2020 and 2301 persons were advised, mainly on sub-measures 6.1. and 6.3 .

The information provided allows us to conclude that as of today the support for farmers under the RDP is more towards investments in the farms themselves than towards direct support of marketing activities, incl. short supply chains.

Also interesting is the dynamics of the interest of the farmers in support under the abovementioned measures for the period 01.01.2014 - 30.06.2017 (Chart 1). 
STANIMIROVA M., et al.

Table 1. Consultations carried out and farmers advised on measures under the RDP 2014-2020, related to the development of short supply chains

\begin{tabular}{|l|c|c|c|c|}
\hline RDP sub-measure & $\begin{array}{l}\text { Number of } \\
\text { consultations }\end{array}$ & $\begin{array}{l}\text { Correlation to the } \\
\text { total number (\%) }\end{array}$ & $\begin{array}{l}\text { Number of } \\
\text { persons consulted }\end{array}$ & $\begin{array}{l}\text { Correlation to the } \\
\text { total number (\%) }\end{array}$ \\
\hline $\begin{array}{l}\text { 4.2. "Investment in } \\
\text { processing / marketing of } \\
\text { agricultural products" }\end{array}$ & 20 & 0.01 & 20 & 0.01 \\
\hline $\begin{array}{l}\text { 6.1. "Business start-up aid } \\
\text { for young farmers " }\end{array}$ & 533 & 0.36 & 669 & 0.29 \\
\hline $\begin{array}{l}6.3 \text { "Start-up aid for the } \\
\text { development of small } \\
\text { farms" }\end{array}$ & 927 & 0.63 & 1612 & 0.70 \\
\hline $\begin{array}{l}16.4 \text { "Support for horizontal } \\
\text { and vertical cooperation } \\
\text { among supply chain actors" }\end{array}$ & 0 & 0 & 0 & 0 \\
\hline Total: & 1480 & 1 & 2301 & 1 \\
\hline
\end{tabular}

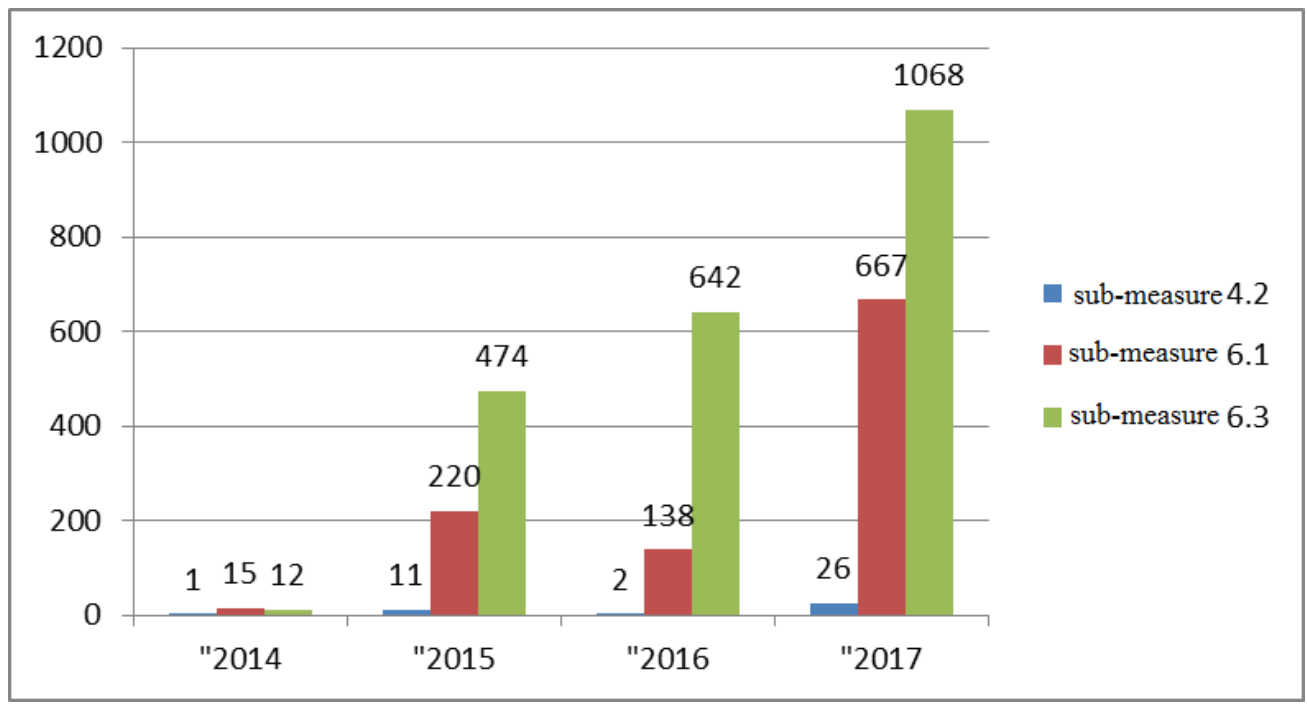

Chart 1. Number of advised farmers in the district of Varna under measures from the RDP 2014-2020, related to investments in short supply chains

Although the interest in supporting investments in processing and marketing of agricultural products (sub-measure 4.2) is rather weak over the analyzed period, it is noticeable that the number of farmers advised on this sub-measure has increased. There is a very strong statistically significant relationship between the number of advised farmers under sub-measures 6.1 and 6.3 and the interest in sub-measure 4.2 (correlation coefficients respectively 0.941 and 0.911 ). This gives a reason to assume that the support for farm development builds capacity for subsequent investment in activities, connected to processing and marketing of agricultural products and is the basis for developing innovative channels for the realization of products and the development of short supply chains. The higher dependence ratio of submeasure 6.1 "Business start-up aid for young farmers" makes it possible to assume that young farmers are more receptive to innovative marketing channels, such as short supply chains.

Regardless of the small number of consultations related to the marketing and processing of agricultural products in our country, positive examples can be given related to the realization of production in small and medium farms, among which:

1. Purchasing milk vending machines (new and second hand ones) by cow milk manufacturers and their installation in their own shops and premises having the status of commercial sites. This creates an opportunity to provide fresh milk of high quality at a good price and hygiene conditions meeting the requirements under the national legislation. This way of disposal has a number of 
advantages of which some of the more important are: easy maintenance, mobility, opportunity for constant control on parameters including by smartphone and minimum risk for the ready production. The disadvantages of these sales are basically the small quantities of sold products and dependence on other actors which is characteristic for almost all forms of short supply chains.

2. Investments in processing of the produced milk by farmers with medium-sized farms for lactic acid products such as yogurt, cheese, yellow cheese, curd, qatiq and ayran. The processing activities are carried out in small or medium-sized companies, financed by own funds or by the RDP. A growing number of those manufacturers sell their products in their own shop, which requests a higher level of quality in the production of milk and lactic acid products in the region.

3. Also in the realization of fruit there is interest in processing and production of products with added value - juices, bottled fruit, jams etc. These producers sell a significant part of their products to hotels in the tourist resorts near Varna as well as on farmers' markets and fairs.

4. Direct sales of bee products manufactured in the district of Varna. Organically produced honey as per contract signed with a certification body and a completed transition period, is to be sold immediately within the marketing year. The production is mainly sold by direct deliveries of small lots with preconcluded contracts. The organic products monoflorous honey, propolis and beeswax, such as small figurines, aromatic candles and bee pollen in packages, are sold combined with souvenirs from the region. Organic products are easily sold by owners of rural tourism accommodation - guest houses and small family hotels.

5. There are farms offering equestrian sports and direct observation of how cow or sheep milk is produced and processed.

6. Strive to establish own trademark for combined activities such as "Tomato House" rural tourism, production on fresh vegetables, mainly tomatoes and "lyutenitsa" (a kind of chutney) with a trademark and a label.

Potential opportunities, but poor development is observed in the direct realization of meat products (mainly poultry and rabbits). The opportunities to process meat are not used. This is largely due to the stricter forms of control by public authorities on the production and sales. At the same time, such shops for direct sales of meat from local and indigenous breeds exist in Austria, Poland and Spain and are under a special more relaxed control regime. Direct sales of fresh eggs are also not legally regulated. A major problem for small and medium-sized farms in the priority sectors - livestock farming, fruit and vegetables, is the realization of the production. In these farms there are other important issues that are relevant for the whole branch - lack of a clear agricultural development policy beyond 2020, serious personnel problems at all levels and poor awareness of the impact of environmental factors on agricultural activities.

We can conclude that the cooperation between the producers is an essential condition for the development of short chains. In some varieties there is an intermediary which collects the production of the different producers and delivers it to the end user. The development of short chains in the different business spheres is related to the consideration of the specifics of the relevant products and markets. In agriculture, the process of determining direct supply chains is usually associated with a limited scale business activity and a clearly defined circle of consumers. Entrepreneurs working in the agriculture branch should take into account the fact that by differences in the demand and the competition conditions, consumers react in a specific way to the products they are offered. Understanding the mechanism of these responses is a condition for modifying offers and creating prerequisites for success in direct marketing strategies. It is essential that the business professionals know the different elements of the market and the way they interact to successfully operate the short chains.

The short distribution chains are an innovative channel for marketing agricultural products in Bulgaria and their development and financing through European Agricultural Fund for Rural Development creates conditions for competitive advantages and development of sustainable small agricultural farms in Bulgaria.

\section{REFERENCES}

1. National Rural Network. Condition and necessities needs for the development of short food supply chains in Bulgaria, Report of Thematic Working Group 1 "Short supply chains", Sofia, 2013.

2. Stanimirov, E. and M. Stanimirova. Competitiveness and sustainable development capacity of the economic subjects in the rural areas of the Region of Varna. Publshing house "Nauka i ikonomika", University of Varna, 2014. 
3. Aubert, M. and Enjolras, G., 2013. Quelles incitations pour la vente au détail ? Une analyse économique et financière des exploitations agricoles françaises. INRASFER-CIRAD, AngersFrance, December 2013.

4. Broderick, S., Wright, V., and Kristiansen, P., 2011. Cross-Case Analysis of ProducerDriven Marketing Channels in Australia. British Food Journal, 113(10), 1217-1228.

5. François M., Ricci C. et al. Marketing local products. Short and long distribution channels. LEADER European Observatory/AEIDL, 2000.

6. Kneafsey M., Venn L., Schmutz U., Balázs B., Trenchard L. and oth. Short Food Supply Chains and Local Food Systems in the EU. A State of Play of their Socio-
STANIMIROVA M., et al.

Economic Characteristics. European Commission. Joint Research Centre Institute for Prospective Technological Studies, Seville (Spain), 2013.

7. Magali A., Geoffroy E. Do short food supply chains go hand in hand with environment-friendly practices? International Conference of Agricultural Economics. France, 2015.

8. Marsden, T., Banks, J., and Bristow, G. (2000) Food Supply Chain Approaches: Exploring their Role in Rural Development. Sociologia Ruralis 40 (4), 424-438.

9. Renting, H., Marsden, T., and Banks, J. (2003) Understanding Alternative Food Networks: Exploring the Role of Short Food Supply Chains in Rural Development. Environment and Planning A 35, 393-411. 